\title{
E-mental health preferences of Veterans with and without probable posttraumatic stress disorder
}

\author{
Julia M. Whealin, PhD; ${ }^{1-2 *}$ L. Alana Seibert-Hatalsky, PhD; ${ }^{1}$ Jennifer Willett Howell, PhD; ${ }^{1}$ Jack Tsai, PhD $^{\mathbf{3}}$ \\ ${ }^{1}$ Department of Veterans Affairs (VA) Pacific Islands Health Care System, Honolulu, HI; ${ }^{2}$ Department of Psychiatry, \\ University of Hawaii School of Medicine, Manoa, HI; ${ }^{3}$ VA New England Mental Illness, Research, Education, and \\ Clinical Center, West Haven, CT, and Department of Psychiatry, Yale School of Medicine, New Haven, CT
}

\begin{abstract}
Mental health care practices supported by electronic communication, referred to as e-mental health, offer ways to increase access to mental health resources. In recent years, e-mental health interventions using clinical video teleconferencing, Internet-based interventions, social networking sites, and telephones have emerged as viable, cost-effective methods to augment traditional service delivery. Whereas some research evaluates attitudes about e-mental health, few studies have assessed interest in using these approaches in a contemporary sample of U.S. Veterans. This study sought to understand willingness to use e-mental health in a diverse group of Veterans residing in Hawaii. Mailed surveys were completed by 600 Operation Iraqi Freedom/Operation Enduring Freedom Veterans and National Guard members. Results suggest that overall willingness to use e-mental health ranged from $32.2 \%$ to $56.7 \%$ depending on modality type. Importantly, Veterans who screened positive for posttraumatic stress disorder (PTSD) were significantly less likely to report willingness to use each e-mental health modality than their peers without PTSD, despite their greater desire for mental health services. These results suggest that despite solutions to logistical barriers afforded via e-mental health services, certain barriers to mental health care may persist, especially among Veterans who screen positive for PTSD.
\end{abstract}

Key words: barriers to care, e-mental health, OIF/OEF, posttraumatic stress disorder, preferences, rural health, technology, telemental health, treatment accessibility, Veterans.

\section{INTRODUCTION}

More than 30 percent of recent Veterans entering the U.S. Department of Veterans Affairs (VA) healthcare system are diagnosed with a mental disorder. One of the most common diagnoses is posttraumatic stress disorder (PTSD), given to 52 percent of those receiving mental health diagnoses [1-2]. Moreover, an estimated 41 percent of Veterans enrolled in VA care reside in rural settings, including a disproportionate number of younger Veterans and female Veterans returning from Operation Iraqi Freedom (OIF) and Operation Enduring Freedom (OEF) [3]. To meet the needs of the changing Veteran population, the Veterans Health Administration (VHA) is tasked with increasing access to and use of mental health services for geographically and culturally diverse Veterans. The exponential advancement in society's use of

\footnotetext{
Abbreviations: $\mathrm{CI}=$ confidence interval, $\mathrm{CVT}=$ clinical video teleconferencing, $\mathrm{OEF}=$ Operation Enduring Freedom, OIF = Operation Iraqi Freedom, PCL-C $=$ PTSD Checklist-Civilian Version, PTSD $=$ posttraumatic stress disorder, SHTSUS = Self-Help and Treatment Services Utilization Survey, VA = Department of Veterans Affairs, VHA = Veterans Health Administration.

*Address all correspondence to Julia M. Whealin, PhD; VA Pacific Islands Health Care System, 3375 Koapaka St, Suite I-560, Honolulu, HI 96819; 808-566-1546.

Email: Julia.Whealin@va.gov

http://dx.doi.org/10.1682/JRRD.2014.04.0113
} 
technology, and the resultant field of e-mental health, provide a great opportunity to surmount current barriers many Veterans face when accessing mental health care. A number of resources have been developed to meet the needs of Veterans diagnosed with PTSD, yet few studies have examined the willingness to use technology-based mental health treatment approaches. Moreover, rather than ameliorate health disparities, current e-health tools may maintain or actually widen healthcare inequities [4]. Therefore, understanding preferences related to e-health is particularly important within ethno-racially and geographically diverse Veterans.

Recent research has revealed that the majority of Veterans with a mental disorder underuse mental health services [5]. Among OIF/OEF Active Duty Veterans, only 23 to 40 percent of those with mental health diagnoses actually sought mental health care in person [6]. Notably, only 9.5 percent of Veterans newly diagnosed with PTSD during a VHA visit follow through with the recommended course of VHA PTSD treatment [2], which has led the VHA to seek solutions to assist Veterans in addressing their PTSD.

A well-documented barrier to Veteran use of mental health services is stigma [7-10]. Compared with Veterans without PTSD, Veterans with PTSD report more stigma related to mental health services [7,11]. Additionally, Veterans with PTSD often report a strong desire to avoid treatment as a means of avoiding trauma-related feelings and memories [8].

Aside from stigma and avoidance, access to mental health care can be limited by a variety of logistical concerns, including geographical barriers (e.g., inadequate transportation), temporal barriers (e.g., difficulty scheduling appointments), and financial barriers [12-13]. Logistical barriers to care are an even greater challenge for those Veterans who reside in rural communities [14]. Among Veterans who live in rural areas, the distance required to travel to obtain services in person substantially reduces service use and has been identified as the primary barrier to receipt of treatment [15]. Logistical barriers to healthcare services are common within the Pacific Islands, where approximately half of the population lives in areas that are classified as rural or highly rural [16].

A growing development of novel technological modalities in mental health may potentially reduce logistical and personal barriers to care. Mental health care practice supported by electronic processes and communication, referred to as e-mental health, provides a number of potential solutions to service barriers. The VHA has become a leader in the development and delivery of healthcare services via synchronous (real-time) clinical video teleconferencing (CVT), often referred to as telemental health [1718]. Additionally, the VHA has developed computer and mobile telephone applications, such as the Prolonged Exposure Coach [12]. Veterans may also access other emental health resources currently being tested by the VHA as well as resources outside of the VHA. These include telephone-based interventions, telephone texting exchanges, online computer-based interventions, and social networking sites such as Facebook.

\section{Efficacy of Current E-Mental Health Modalities}

\section{Clinical Video Teleconferencing}

Research in the last $10 \mathrm{yr}$ has begun to examine the efficacy of e-mental health technologies as a supplement to or, in some cases, a replacement for traditional face-toface services. A commonly used e-mental health modality within the VHA is CVT, which is used to connect a Veteran with a provider through a television-type screen, computer monitor, or interfaced tablet. Often, the provider is located at a VA medical center and the Veteran is located at a smaller satellite location such as a community-based outpatient clinic. This modality requires staff to coordinate room scheduling and equipment setup at both locations. More recent advances are also allowing for home-based CVT, in which a provider connects over video with a Veteran located in his or her house. In homebased CVT, the use of Internet-enabled tablets to connect Veterans with providers has eliminated the need for Internet access, which can be problematic for some rural Veterans [19]. Studies examining clinical efficacy indicate that CVT treatment outcomes are comparable with inperson delivery [20-21], including treatment of PTSD $[18,22]$.

\section{Internet-Based Interventions}

Care delivered via Internet interventions also appears to be a promising e-mental health modality. Interventions may be static (e.g., providing information) or interactive (i.e., tailored to the responses input by the user). Additionally, the intervention can serve a variety of purposes, such as real-time symptom monitoring and homework assignment [23]. For example, an Internet-based intervention for combat-related mental distress that included 
facilitated peer support was found to decrease depression symptoms and social stigma related to mental health issues among combat Veterans [24]. Mental health providers' direct clinical involvement in self-guided Internet interventions varies greatly, and most current interventions are used as adjunct to or in lieu of traditional psychotherapy. Researchers who have evaluated online mental health interventions have found that they have the potential to be as effective as in-person services for a range of difficulties, including PTSD and other postdeployment problems [25].

\section{Telephone- and Mobile Device-Based Interventions}

The application of telephone technology to mental health care has been evaluated as well [26-29]. The majority of the U.S. population owns landline (e.g., wire transmission) telephones [30], and costs associated with telephone use are modest [31]. Studies to date have found that treatment via telephone is effective in increasing motivation for treatment [32-33]; increasing engagement in care [34]; and reducing symptoms of PTSD, depression, and anxiety [26-29]. With the rapid expansion of cellular telephone use, text messages have also begun to be used to enhance mental health treatment. Both uniform text messages and text messages tailored to the individual have been delivered to promote positive mental health [35-36]. Research suggests that text messages are most effective for positive short-term behavioral outcomes such as weight loss [37], reducing alcohol use [38], and smoking cessation [39]. Additionally, mobile smartphones or similarly capable devices (i.e., tablets) are now being used to provide e-mental health resources [12]. Erbes et al. assessed current VA patients with PTSD ( $n=188)$ for their interest in using mobile technology as a means to access PTSD resources [40]. The majority of Veterans $(76 \%)$ reported having access to a smartphone or similar device (i.e., tablet), but only 10 percent reported using VA e-health PTSD resources. However, a larger percentage (ranging from $56 \%$ to $76 \%$ depending on modality) of Veterans with current access to a mobile device expressed interest in using technology to access treatment for PTSD. Whereas younger age predicted owning a mobile device, age did not predict use of or interest in e-health resources among those who owned a device [40].

\section{Social Networking}

The Internet also enables social networking as a method of engaging with others who share similar problems in a relatively anonymous manner via social networking sites and online support groups. Over 70 percent of young adults and 40 percent of adults over age 30 in the United States use social networks [41]. Pertinently, in a survey distributed to young adults with a mental health diagnosis who were involved with the National Alliance on Mental Illness, the majority (94\%) reported use of social networking sites [42]. Christensen et al. noted significant variability in quality of social networking sites for the treatment of PTSD as well as other anxiety and mood disorders [43]. Nonetheless, they identified several sites as high quality. At present, social networking has shown promise as an e-mental health tool in some treatment areas, including increasing perceived social support [44] and decreasing stigma [45]. Conclusive evidence for social networking's clinical efficacy and applicability to further psychological interventions remains to be seen [46].

In summary, e-mental health represents a means to bridge the gap between need and receipt of mental health treatment, especially for rural Veterans. However, data are lacking on Veterans' interest in using e-mental health modalities as a means for accessing mental health services.

\section{Theoretical Approach Used in Present Study}

Andersen's Behavioral Model is commonly employed as a tool to evaluate predictors of service interest and use [47]. This model identifies predictors of healthcare use as a function of three determining factors. "Predisposing factors" are those that exist prior to or independent of the onset of illness, such as being female, being married [48-50], having a higher education level [51], and having ethno-racial minority status [52]. A second determinant of use, according to the model, is "enabling factors," those contextual factors that influence access to care, such as the travel distance to obtain services $[49,53]$. Third, "need factors" include the presence of mental disorders or poor mental health quality of life $[6,10,48,54-56]$. Whereas need factors are generally associated with increased use of services, research has also consistently revealed higher rates of perceived barriers to care among Veterans with PTSD [6]. Thus, the role of PTSD as a need factor remains unclear. 


\section{Study Aims and Hypotheses}

The overall purpose of the present study was twofold. The first aim was to address the current gaps in research by identifying willingness to use a variety of emental health modalities as a means for accessing mental health services in diverse Veterans with and without a positive screen for PTSD. Based on previous studies that indicate that Veterans with PTSD are interested in using e-health modalities $[22,24,40]$ and drawing from Andersen's Behavioral Model [47], we hypothesized that Veterans with PTSD would report greater willingness to use emental health than Veterans without PTSD. Additionally, research has not examined interest in e-health modalities in Veterans who express a need for traditional mental health services. Therefore, for exploratory purposes, we also examined trends in interest in e-health services among Veterans who did and did not express a need for healthcare services.

A second aim of this study was to identify predictors of interest in using e-mental health modalities as a means for accessing services. Drawing from Andersen's Behavioral Model [47] and previous research, we hypothesized that predisposing factors (younger age, female sex, being married or cohabitating, minority status) [52], enabling factors (residing in a rural area) $[49,53]$, and need factors (having PTSD, desiring help for an emotional problem) $[6,10,48,54-56]$ would collectively be related to greater willingness to use e-mental health. To accomplish these goals, we surveyed a diverse sample of OIF/OEF Veterans and National Guard members in Hawaii.

\section{METHODS}

\section{Procedure}

A survey of attitudes about e-mental health modalities among Veterans and National Guard members was conducted using a multistage mailing procedure [57]. A cover letter and fact sheet explaining the study and consent process were initially mailed, followed by three reminder letters. An incentive of \$20 was included with the survey to provide remuneration for Veterans' and National Guard members' time. Rural and urban coding followed VHA guidelines in which urban residents are defined as those living in a U.S. Census-defined urbanized area [16]. Rural residents included anyone not defined as urban.

\section{Participants}

Participants were a Hawaiian sample of Veterans and National Guard members who served after September 11, 2001, assessed in early 2011 and stratified by rural or urban residence. Veterans were randomly selected from a roster of 2,565 OIF/OEF Veterans residing in Hawaii. Of the 400 surveys mailed, 233 were completed and returned (58\% response rate). National Guard members were randomly selected from a list of all enrolled National Guard members in the state of Hawaii $(N=5,300)$. Of the 800 surveys mailed, 390 were completed and returned $(49 \%$ response rate). Of the total 623 surveys received, 600 provided usable data for the purposes of this study. Veterans and National Guard members did not differ on sex, age, education level, rural versus urban residence, or marital status. However, compared with Veterans, National Guard members were less likely to screen positive for PTSD $(n=$ 55 vs 126 Veterans; $X=61.03, p<0.001)$ or to desire help for an emotional problem ( $n=47$ vs 91 Veterans; $X=$ 61.03, $p<0.001)$ and more likely to identify as Asian American ( $n=163$ vs 55 Veterans) or Native Hawaiian/ Pacific Islander ( $n=96$ vs 67 Veterans) than those identifying as White/Caucasian ( $n=52$ vs 69 Veterans) or other ( $n=46$ vs 52 Veterans) $(X=26.53, p<0.001)$. Our sample did not differ from national samples of Veterans or National Guard members who served after September 11, 2001, except that the present sample was more likely to be married and to identify as Asian American or Native Hawaiian/Pacific Islander. Furthermore, our sample did not vary by age, sex, or relationship status compared with the general population of Hawaiian Veterans or National Guard members (which from this point forward, for convenience purposes, we will refer to as Veterans).

\section{Measures}

\section{Demographics}

Veterans were asked to self-report their age, sex, level of education, marital status, and the racial or ethnic group(s) with which they most identified. Responses to race or ethnicity were subdivided into Asian American/ Filipino, Native Hawaiian/Pacific Islander, White/Caucasian, and other (e.g., American Indian/Alaska Native, Black/African American, Hispanic/Latino).

\section{Posttraumatic Stress Disorder}

PTSD symptoms were assessed with the 17-item PTSD Checklist-Civilian Version (PCL-C) [58]. The 
PCL-C is a self-report screening measure designed to assess symptoms of PTSD according to Diagnostic and Statistical Manual of Mental Disorders-4th Edition diagnostic criteria. The civilian version of this scale was used because we were interested in PTSD status regardless of type of traumatic stressor. Respondents were asked to rate their degree of distress for each symptom in relation to a self-identified traumatic or stressful event on a 5-point Likert scale from 1 (not at all) to 5 (extremely). Consistent with recommendations for use in nonclinical military samples [59], a total sum score of $\geq 35$ was considered a probable positive screen for PTSD. In contemporary military populations, this cutoff has been shown to discriminate level of functioning [60] and maintains a high level of specificity (0.91) along with reasonable sensitivity [59].

The PCL-C was used instead of a clinician-administered assessment or a review of VA medical records because our study was based on a mail survey of a community sample of Veterans (not all were engaged in VA services and had a medical record), which allowed for sampling a greater number of Veterans and with a higher response rate than other assessment methods because surveys were anonymous and self-administered. Moreover, the PCL-C was developed by the VHA and is regularly used to assess hundreds of thousands of individuals in clinical practice and research annually. Studies have shown the PCL-C has good validity, diagnostic efficiency, and reliability [59,61-62]. In our study, the PCL-C showed good internal consistency $(\alpha=0.97)$.

\section{Mental Health Need and Willingness to Use E-Mental Health}

Perceived desire for help with an emotional problem within the past $3 \mathrm{mo}$ and willingness to use e-mental health were measured via the Self-Help and Treatment Services Utilization Survey (SHTSUS) [63]. Items that assessed interest in treatment services prefaced with "If you needed or wanted help for an emotional problem" were adapted to include e-health resources. Specifically, Veterans were asked whether or not (yes or no) they would be willing to use each of seven e-mental health treatment modalities: (1) CVT in a clinic, (2) CVT in their home, (3) telephone call from a provider, (4) personalized email messages, (5) text messages from a provider, (6) Internet-based interventions (without a provider), or (7) social networking with a peer group. A variable summing these items served as an index of general willingness to use e-mental health services.

\section{Statistical Analyses}

Data distribution and descriptive statistics were examined to ensure that all variables met assumptions for parametric analyses. Descriptive summary statistics were computed and reported for all demographic, military, and psychosocial variables. Outliers were examined and none were identified that skewed the results. Eight participants had minimal item-level data missing (1-3 items each) on the SHTSUS e-health items. Maximum likelihood procedures were employed to estimate these values [63]. Chisquare tests were conducted to examine the relation between demographic variables, PTSD status, and willingness to use e-mental health services. Independent samples $t$-tests and analyses of variance, as appropriate, were computed to examine differences between Veterans with and without probable PTSD. Finally, a multivariable linear regression was computed to determine which variables predicted willingness to use e-mental health modalities. Because PTSD status and desire for help were correlated $(\alpha=0.56)$, desire for help was excluded from the analysis. Intercorrelations among all remaining predictor variables were $<0.40$.

\section{RESULTS}

Demographic variables were compared to determine whether differences existed between Veterans with probable PTSD $(n=181)$ and those without PTSD $(n=419)$. Compared with Veterans in the non-PTSD group, Veterans with probable PTSD were more likely to live in a rural area, to be categorized as "other" ethno-racially (e.g., those who identified as American Indian/Alaska Native, Black/African American, Hispanic/Latino, or as more than one ethno-racial category), and to report a desire for help for a mental health problem in the past 3 mo (Table 1). There were no significant differences based on age, sex, marital status, or education level.

\section{Posttraumatic Stress Disorder and E-Mental Health Interest}

Within the entire sample, overall willingness to use e-mental health resources ranged from 32.2 percent for text messaging to 56.7 percent for telephone calls from providers (Table 2). Within Veterans with probable PTSD, willingness to use e-mental health interventions ranged from a low of 20.4 percent for CVT in a VHA clinic to a high of 37.6 percent for telephone calls to the home. Within the non-PTSD group, willingness to 
Table 1.

Characteristics of Veterans with and without probable posttraumatic stress disorder (PTSD) and their desire for mental health treatment. Data presented as mean \pm standard deviation or frequency $(\%)$.

\begin{tabular}{|c|c|c|c|c|}
\hline Characteristics & $\begin{array}{l}\text { No PTSD } \\
(n=419)\end{array}$ & $\begin{array}{c}\text { Probable PTSD } \\
(n=181)\end{array}$ & $\begin{array}{c}\text { Total } \\
(n=600)\end{array}$ & $\begin{array}{c}\text { Difference Score } \\
\left(t / \chi^{2}\right)\end{array}$ \\
\hline $\operatorname{Sex}^{*}$ & & & & $\chi^{2}=2.05$ \\
\hline Female & $73(17.5)$ & $23(12.8)$ & $96(16.1)$ & \\
\hline Ethnicity & & & & $\chi^{2}=22.30^{\dagger}$ \\
\hline Asian American/Filipino & $176(42.0)$ & $42(23.2)$ & $218(36.3)$ & \\
\hline Other & $56(13.4)$ & $42(23.2)$ & $98(16.3)$ & \\
\hline Location & & & & $\chi^{2}=7.84$ \\
\hline Urban & $222(53.0)$ & $80(44.2)$ & $302(50.3)$ & \\
\hline Rural & $197(47.0)$ & $101(55.8)$ & $298(49.7)$ & \\
\hline Education $^{*}$ & & & & $\chi^{2}=7.38^{*}$ \\
\hline Married or Living with Partner & $242(58.5)$ & $104(58.1)$ & $346(58.3)$ & \\
\hline Not Married or Not Living with Partner & $172(41.5)$ & $75(41.9)$ & $247(41.7)$ & \\
\hline Desired Help for Mental Health Problem in Past 3 mo & & & & $\chi^{2}=185.10^{\dagger}$ \\
\hline Yes & $32(7.6)$ & $106(58.6)$ & $138(23.0)$ & \\
\hline No & $387(92.4)$ & $75(41.4)$ & $462(77.0)$ & \\
\hline
\end{tabular}

Note: PTSD measured by PTSD Checklist-Civilian Version.

* Some participant data are missing from this demographic characteristic.

${ }^{\dagger} p<0.001$.

$\pm p<0.05$.

Table 2.

Reported willingness to use e-mental health services among Veterans with and without probable posttraumatic stress disorder (PTSD). Data presented as frequency $(\%)$.

\begin{tabular}{|c|c|c|c|c|}
\hline E-Mental Health Service & $\begin{array}{l}\text { No PTSD } \\
(n=418)\end{array}$ & $\begin{array}{c}\text { Probable PTSD } \\
(n=182)\end{array}$ & $\begin{array}{c}\text { Total } \\
(n=600)\end{array}$ & $\chi^{2}$ \\
\hline CVT in Clinic & $191(45.6)$ & $37(20.4)$ & $228(38.0)$ & $33.92^{*}$ \\
\hline Online Computer-Based Interventions & $212(50.6)$ & $56(30.9)$ & $268(44.7)$ & $19.76^{*}$ \\
\hline Personalized Messages to Computer & $211(50.4)$ & $51(28.2)$ & $262(43.7)$ & $25.28^{*}$ \\
\hline Text Messages to Cellular Telephone & $149(35.6)$ & $44(24.3)$ & $193(32.2)$ & $7.33^{\dagger}$ \\
\hline
\end{tabular}

use e-mental health ranged from a low of 35.6 percent for text messaging to a cellular telephone to a high of 67.9 percent for telephone calls to the home. Chi-square analyses indicated that Veterans in the non-PTSD group were more likely than Veterans with probable PTSD to report willingness to use each modality (Table 2).

\section{Mental Health Need and E-Mental Health Interest}

A $t$-test was conducted to compare the willingness to use e-mental health in Veterans who reported a desire for help for a mental health problem within the past 3 mo with those who did not report a desire for help. Results showed that Veterans who reported desiring help within 
the past 3 mo were significantly less likely to express willingness to use any e-mental health modality when compared with Veterans who did not report desiring help $(t(598)=4.60, p<0.001)$.

\section{Correlates of E-Mental Health Interest}

A multivariable linear regression analysis was conducted to examine predictors of willingness to use emental health services. Predisposing factors (age, sex, marital status, education level, and race or ethnicity), enabling factors (rural location), and need factors (PTSD status) were entered as independent variables. Results showed that the model accounted for 29 percent of the variance $\left(R^{2}=0.09, F(7,573)=7.68\right)$. As shown in Table 3, only PTSD status $(t=-0.618, p<0.001,95 \%$ confidence interval $[\mathrm{CI}]=-1.87$ to -0.97$)$ and education $(t=2.35, p<0.05,95 \% \mathrm{CI}=0.07$ to 0.79$])$ were correlated with willingness to use e-mental health services. Probable PTSD status predicted lower willingness to use e-mental health. A post hoc analysis of variance indicated that a greater number of Veterans who had a postcollege education level were willing to use e-mental health compared with Veterans with only undergraduate education $(F=0.72, p>0.05)$ or Veterans who had a high school degree or less education $(F=1.08, p<0.01)$.

\section{DISCUSSION}

Among a sample of Veterans in Hawaii, 32 to 57 percent were receptive to e-mental health, depending on modality type. There were differences in willingness to use e-mental health resources between those with and without probable PTSD. Only 20 to 38 percent of Veterans who screened positive for PTSD reported a willing- ness to use most e-mental health modalities, compared with 36 to 68 percent of Veterans who did not screen positive for PTSD. Studies have found that the majority of VHA patients diagnosed with PTSD do not follow through with the recommended course of mental health treatment [2,5]. Thus, our finding appears important because the need to reach Veterans with PTSD remains a pressing concern for the VHA.

Additionally, Veterans who desired help for a mental health problem within the past 3 mo were significantly less likely to express willingness to use e-mental health services than Veterans who did not desire help. Despite the number of challenges Veterans face in accessing traditional, in-person mental health services, our findings imply that e-mental health may not remediate other service barriers to care facing Veterans, particularly those with PTSD. Although not directly assessed within this study, these numbers are comparable with reported willingness to attend traditional mental health treatment [64], even if the Veteran is acknowledging awareness of distress.

Low education level and PTSD status were correlated with lower willingness to use e-mental health resources, even when controlling for other variables (age, education level, sex, and race or ethnicity). These correlations were relatively small but are consistent with recent research that has found that Veterans who have lower levels of education are less likely to use the Internet [65-66] and the VHA's personal electronic health record system (My HealtheVet) [66]. It may be that Veterans with low education have less familiarity and/or comfort with technology, which decreases their willingness to participate in e-mental health. Veterans with low education levels may also have less access to certain technologies: a potential problem identified among Veterans with severe mental illness leading to a "digital divide" [67]. Because Veterans with

Table 3.

Linear regression analyses by relationship between demographic factors and willingness to use e-mental health services.

\begin{tabular}{|c|c|c|c|c|c|}
\hline Variable & Unstandardized $\beta$ & Standardized $\beta$ & $t$-Value & $p$-Value & 95\% CI* \\
\hline$\overline{\text { Age }}$ & -0.009 & -0.037 & -0.894 & 0.37 & -0.03 to 0.01 \\
\hline Sex & 0.121 & 0.017 & 0.423 & 0.67 & -0.44 to 0.68 \\
\hline Ethnicity & -0.115 & -0.050 & -1.245 & 0.21 & -0.30 to 0.07 \\
\hline Relationship Status & -0.036 & -0.006 & -0.155 & 0.88 & -0.50 to 0.42 \\
\hline Education & 0.428 & 0.098 & 2.349 & 0.02 & 0.07 to 0.79 \\
\hline
\end{tabular}

Note: PTSD measured by PTSD Checklist-Civilian Version.

* 95 percent CI of unstandardized beta values.

$\mathrm{CI}=$ confidence interval, $\mathrm{PTSD}=$ posttraumatic stress disorder. 
less education are also less likely to access traditional mental health services [68], additional efforts are needed to identify and overcome mental health treatment barriers for these Veterans.

Previous research that assessed current VA patients with PTSD for their interest in using mobile technology as a means to access e-health found that only 10 percent reported using VA e-health PTSD resources, despite the majority of Veterans $(76 \%)$ who reported having access to mobile technology (i.e., tablets) [40]. A larger percentage (between $56 \%$ and $76 \%$, depending upon type of modality) of Veterans in that sample with current access to a mobile device expressed interest in using technology to access treatment for PTSD [40]. In the present study, only a minority of Veterans who screened positive for PTSD (20.4\%-37.6\%) expressed interest in e-mental health services. A number of factors may account for the differences in results between these two studies. First, the present study did not assess for access. Rates of interest would likely be higher if the present analysis was limited to Veterans who reported having access to technology. Second, the present investigation assessed a nontreatment sample of Veterans. Perhaps due to occupational and attitudinal differences, the present group may be less invested in mental health resources than Veterans who are currently receiving mental health treatment. Finally, the present sample consisted of ethno-racially and geographically diverse Veterans who may respond differently than largely urban, White/Caucasian Veteran samples. Evaluation of current e-health products suggests that some resources may not adequately address the needs of minority populations and therefore may foster health inequities [4].

The modalities endorsed by the highest number of Veterans with probable PTSD were telephone calls from a provider to the home (endorsed by $37.6 \%$ ) and social networking with peers (endorsed by $34.8 \%$ ). Telephone calls may be perceived as more confidential by Veterans than the newer e-mental health modalities. Additionally, social networking affords anonymity to users who do not provide identifying information. It may be that stigma and related privacy concerns affect Veterans' reluctance to use other modalities. Other potential reasons underlying the low levels of e-mental health interest among Veterans with PTSD may be lack of experience using these technological modalities, information processing difficulties secondary to PTSD, and/or the desire to avoid trauma-related thoughts and feelings [8]. It will be important to assess these factors in follow-up studies.

Some research has indicated that training can improve attitudes and self-efficacy related to e-health resources [69-71]. Because VHA providers have opportunities to promote e-mental health to patients as a potential form of care, training is needed so that staff members have up-to-date knowledge about these resources, including training on how to best disseminate e-mental health resources to Veterans. Recent research has found that providers' attitudes about e-mental health services are often negative and based on outdated beliefs, including beliefs that services provided by CVT have poorer rapport levels, lower clinical efficacy, or cost more than inperson care [72]. In the past 10 years, a number of new emental health resources have become available, and advancements to e-mental health technology have made its use more feasible. At the same time, the cost of using e-mental health has decreased considerably, and Health Insurance Portability and Accountability Act-compliant security has become available for computers, tablets, and smartphones [72]. Given these recent advances in the field and research supporting e-mental health efficacy, it seems prudent to have up-to-date training for both VHA staff and Veterans. Staff will also benefit from training by learning to promote these services using approaches that meet the personalized needs of Veterans, including those who may be unfamiliar with technology.

The findings of this research are significant for several reasons. Participants in this study are drawn from a contemporary, community sample of Veterans who may or may not attend the VA. Such populations commonly experience mental health problems but may not attend the VA due to logistical barriers or stigma or because their symptoms are not disabling. The present findings may be representative of attitudes of Veterans in general compared with those who have already initiated care with the VA. Importantly, many e-mental health interventions can be disseminated widely and thus can meet the needs of Veterans both inside and outside of the VA. Another strength of this study is that participants consist of an under-researched and ethno-racially and geographically diverse population of Veterans, half of whom reside in rural locations. Diverse subgroups of Veterans warrant special attention because their needs and preferences can differ from those of commonly researched populations [4]. The relatively low rates of willingness to use e-health found in this population of Veterans warrants further 
investigation in rural and Asian American and Native Hawaiian/Pacific Islander Veterans, other minority groups, and Veterans with mental health problems.

\section{STUDY LIMITATIONS AND NEED FOR FUTURE RESEARCH}

This study did not assess specific Veteran concerns related to the use of e-mental health but instead gauged overall initial interest. Further research is warranted to understand Veterans' specific perspectives on e-mental health, such as lack of familiarity with technology. This survey assessed "willingness" to use e-mental health, which may not translate to actual use; therefore, formal study is needed on the actual use of e-mental health resources. Additionally, the results of this study are based on samples from Hawaii, and so generalizability to other U.S. Veterans is unclear. Further research is also needed to understand the role that factors such as sex, age, education level, and geographic location play in regard to differences in e-mental health preferences and barriers.

\section{CONCLUSIONS}

Results of the present investigation inform a growing, concerted movement to develop and adopt technology-based mental health interventions for Veterans with PTSD. Due to the VHA's mission to provide equitable, accessible, and patient-centered care [12], it is important that VHA providers and administrators recognize that many patients may be reluctant to use e-mental health, independent of treatment need. Additional research is warranted to better understand Veterans' concerns with emental health, particularly in light of our findings that Veterans with probable PTSD are significantly less open to accessing e-mental health treatment. E-mental health holds great potential for improving access and quality of care, especially when there may be barriers to care (as in rural settings). However, staff may need to spend time familiarizing Veterans with e-mental health modalities and technologies, including allaying concerns regarding confidentiality and efficacy. Further research is needed to understand barriers to e-mental health care from the viewpoints of both Veterans and staff to inform development and implementation of e-mental health in the VHA.

\section{ACKNOWLEDGMENTS}

\section{Author Contributions:}

Study concept and design: J. M. Whealin, L. A. Seibert-Hatalsky. Acquisition of data: J. M. Whealin.

Analysis of data: J. M. Whealin, L. A. Seibert-Hatalsky, J. Tsai. Interpretation of data: J. M. Whealin, L. A. Seibert-Hatalsky, J. W. Howell, J. Tsai.

Drafting of manuscript: J. M. Whealin, L. A. Seibert-Hatalsky. Critical revision of manuscript for important intellectual content: J. W. Howell, J. Tsai.

Final approval of manuscript: J. M. Whealin, L. A. Seibert-Hatalsky, J. W. Howell, J. Tsai.

Financial Disclosures: Dr. Tsai has received funding from the Bristol Meyers Squibb Foundation, which had no influence on this work.

There was no role of any study sponsor in study design; in the collection, analysis, or interpretation of data; in the writing of the report; or in the decision to submit the report for publication. The other authors have declared that no competing interests exist.

Funding/Support: This material was based on work supported by the VA Office of Research and Development (Human Services Research and Development Award no. PPO 09-314-1 to Dr. Whealin), the National Center for PTSD, and the VA Pacific Islands Health Care System.

Additional Contributions: Thank you to Sandra Bozik-Lyman, MA, and Dawna Nelson, MSW, for their assistance collecting these data and to the Veterans of Hawaii for their dedicated service. Dr. Howell is now in private practice in Kapolei, Hawaii.

Institutional Review: This research was approved by the VA Pacific Islands Health Care System Institutional Review Board.

Participant Follow-up: The authors have no plans to notify the study subjects of the publication of this article because of a lack of contact information.

Disclaimer: The contents of this article do not necessarily represent the views of the VA or U.S. Government.

\section{REFERENCES}

1. Seal KH, Metzler TJ, Gima KS, Bertenthal D, Maguen S, Marmar CR. Trends and risk factors for mental health diagnoses among Iraq and Afghanistan veterans using Department of Veterans Affairs health care, 2002-2008. Am J Public Health. 2009;99(9):1651-58. [PMID:19608954] http://dx.doi.org/10.2105/AJPH.2008.150284

2. Seal KH, Maguen S, Cohen B, Gima KS, Metzler TJ, Ren L, Bertenthal D, Marmar CR. VA mental health services utilization in Iraq and Afghanistan veterans in the first year of receiving new mental health diagnoses. J Trauma Stress. 2010;23(1):5-16. [PMID:20146392]

http://dx.doi.org/10.1002/jts.20493

3. Skupien MB, Warren SM. Strategic plan refresh: Fiscal years 2012-2014 [Internet]. Washington (DC): Department of Veterans Affairs, Veterans Health Administration, VA Office of Rural Health; 2012 [cited 2014 Feb 26]. Available from: 
http://www.ruralhealth.va.gov/docs/

ORH_StrategicPlanRefresh_FY2012-2014.pdf

4. Bacigalupe G, Askari SF. E-health innovations, collaboration, and healthcare disparities: Developing criteria for culturally competent evaluation. Fam Syst Health. 2013;31(3): 248-63. [PMID:24059273] http://dx.doi.org/10.1037/a0033386

5. Cohen BE, Gima K, Bertenthal D, Kim S, Marmar CR, Seal KH. Mental health diagnoses and utilization of VA non-mental health medical services among returning Iraq and Afghanistan veterans. J Gen Intern Med. 2010;25(1): 18-24. [PMID:19787409] http://dx.doi.org/10.1007/s11606-009-1117-3

6. Hoge CW, Castro CA, Messer SC, McGurk D, Cotting DI, Koffman RL. Combat duty in Iraq and Afghanistan, mental health problems, and barriers to care. N Engl J Med. 2004; 351(1):13-22. [PMID:15229303] http://dx.doi.org/10.1056/NEJMoa040603

7. Pietrzak RH, Johnson DC, Goldstein MB, Malley JC, Southwick SM. Perceived stigma and barriers to mental health care utilization among OEF-OIF veterans. Psychiatr Serv. 2009;60(8):1118-22. [PMID:19648201] http://dx.doi.org/10.1176/ps.2009.60.8.1118

8. Sayer NA, Friedemann-Sanchez G, Spoont M, Murdoch M, Parker LE, Chiros C, Rosenheck R. A qualitative study of determinants of PTSD treatment initiation in veterans. Psychiatry. 2009;72(3):238-55. [PMID:19821647] http://dx.doi.org/10.1521/psyc.2009.72.3.238

9. Stecker T, Fortney JC, Hamilton F, Ajzen I. An assessment of beliefs about mental health care among veterans who served in Iraq. Psychiatr Serv. 2007;58(10):1358-61. [PMID:17914017] http://dx.doi.org/10.1176/ps.2007.58.10.1358

10. Vogt D. Mental health-related beliefs as a barrier to service use for military personnel and veterans: A review. Psychiatr Serv. 2011;62(2):135-42. [PMID:21285091] http://dx.doi.org/10.1176/ps.62.2.pss6202_0135

11. Desai RA, Stefanovics EA, Rosenheck RA. The role of psychiatric diagnosis in satisfaction with primary care: Data from the Department of Veterans Affairs. Med Care. 2005;43(12):1208-16. [PMID:16299432] http://dx.doi.org/10.1097/01.mlr.0000185747.79104.90

12. Fortney JC, Burgess JF Jr, Bosworth HB, Booth BM, Kaboli PJ. A re-conceptualization of access for 21 st century healthcare. J Gen Intern Med. 2011;26(Suppl 2):639-47. [PMID:21989616] http://dx.doi.org/10.1007/s11606-011-1806-6

13. Zinzow HM, Britt TW, McFadden AC, Burnette CM, Gillispie $\mathrm{S}$. Connecting active duty and returning veterans to mental health treatment: Interventions and treatment adaptations that may reduce barriers to care. Clin Psychol Rev.
2012;32(8):741-53. [PMID:23063627]

http://dx.doi.org/10.1016/j.cpr.2012.09.002

14. Weeks WB, Kazis LE, Shen Y, Cong Z, Ren XS, Miller D, Lee A, Perlin JB. Differences in health-related quality of life in rural and urban veterans. Am J Public Health. 2004;94(10):1762-67. [PMID:15451747]

http://dx.doi.org/10.2105/AJPH.94.10.1762

15. Buzza C, Ono SS, Turvey C, Wittrock S, Noble M, Reddy G, Kaboli PJ, Reisinger HS. Distance is relative: Unpacking a principal barrier in rural healthcare. J Gen Intern Med. 2011;26(Suppl 2):648-54. [PMID:21989617] http://dx.doi.org/10.1007/s11606-011-1762-1

16. West AN, Lee RE, Shambaugh-Miller MD, Bair BD, Mueller KJ, Lilly RS, Kaboli PJ, Hawthorne K. Defining "rural" for veterans' health care planning. J Rural Health. 2010;26(4):301-9. [PMID:21029164] http://dx.doi.org/10.1111/j.1748-0361.2010.00298.x

17. Godleski L, Darkins A, Peters J. Outcomes of 98,609 U.S. Department of Veterans Affairs patients enrolled in telemental health services, 2006-2010. Psychiatr Serv. 2012; 63(4):383-85. [PMID:22476305] http://dx.doi.org/10.1176/appi.ps.201100206

18. Gros DF, Strachan M, Ruggiero KJ, Knapp RG, Frueh BC, Egede LE, Lejuez CW, Tuerk PW, Acierno R. Innovative service delivery for secondary prevention of PTSD in atrisk OIF-OEF service men and women. Contemp Clin Trials. 2011;32(1):122-28. [PMID:20951235] http://dx.doi.org/10.1016/j.cct.2010.10.003

19. Barnwell SV, Juretic MA, Hoerster KD, Van de Plasch R, Felker BL. VA Puget Sound Telemental Health Service to rural veterans: A growing program. Psychol Serv. 2012; 9(2):209-11. [PMID:22662737] http://dx.doi.org/10.1037/a0025999

20. Backhaus A, Agha Z, Maglione ML, Repp A, Ross B, Zuest D, Rice-Thorp NM, Lohr J, Thorp SR. Videoconferencing psychotherapy: A systematic review. Psychol Serv. 2012;9(2):111-31. [PMID:22662727] http://dx.doi.org/10.1037/a0027924

21. Hilty DM, Ferrer DC, Parish MB, Johnston B, Callahan EJ, Yellowlees PM. The effectiveness of telemental health: A 2013 review. Telemed J E Health. 2013;19(6):444-54. [PMID:23697504] http://dx.doi.org/10.1089/tmj.2013.0075

22. Morland LA, Hynes AK, Mackintosh MA, Resick PA, Chard KM. Group cognitive processing therapy delivered to veterans via telehealth: A pilot cohort. J Trauma Stress. 2011;24(4):465-69. [PMID:21793047] http://dx.doi.org/10.1002/jts.20661

23. Andersson G, Cuijpers P. Internet-based and other computerized psychological treatments for adult depression: A meta-analysis. Cogn Behav Ther. 2009;38(4):196-205. 


\section{[PMID:20183695]}

http://dx.doi.org/10.1080/16506070903318960

24. Van Voorhees BW, Gollan J, Fogel J. Pilot study of Internet-based early intervention for combat-related mental distress. J Rehabil Res Dev. 2012;49(8):1175-90.

[PMID:23341310]

http://dx.doi.org/10.1682/JRRD.2011.05.0095

25. Amstadter AB, Broman-Fulks J, Zinzow H, Ruggiero KJ, Cercone $\mathrm{J}$. Internet-based interventions for traumatic stress-related mental health problems: A review and suggestion for future research. Clin Psychol Rev. 2009;29(5): 410-20. [PMID:19403215] http://dx.doi.org/10.1016/j.cpr.2009.04.001

26. Bee PE, Bower P, Lovell K, Gilbody S, Richards D, Gask L, Roach P. Psychotherapy mediated by remote communication technologies: A meta-analytic review. BMC Psychiatry. 2008;8(8):60. [PMID:18647396] http://dx.doi.org/10.1186/1471-244X-8-60

27. DuHamel KN, Mosher CE, Winkel G, Labay LE, Rini C, Meschian YM, Austin J, Greene PB, Lawsin CR, Rusiewicz A, Grosskreutz CL, Isola L, Moskowitz CH, Papadopoulos EB, Rowley S, Scigliano E, Burkhalter JE, Hurley KE, Bollinger AR, Redd WH. Randomized clinical trial of telephone-administered cognitive-behavioral therapy to reduce post-traumatic stress disorder and distress symptoms after hematopoietic stem-cell transplantation. J Clin Oncol. 2010;28(23):3754-61. [PMID:20625129] ttp://dx.doi.org/10.1200/JCO.2009.26.8722

28. Morh DC, Vella L, Hart S, Heckman T, Simon G. The effect of telephone-administered psychotherapy on symptoms of depression and attrition: A meta-analysis. Clin Psychol Sci Pract. 2008;15(3):244-53.

29. Hoerster KD, Jakupcak M, Stephenson KR, Fickel JJ, Simons CE, Hedeen A, Dwight-Johnson M, Whealin JM, Chaney E, Felker BL. A pilot trial of telephone-based collaborative care management for PTSD among Iraq/Afghanistan war veterans. Telemed J E Health. 2015;21(1):42-47. [PMID:25405394] http://dx.doi.org/10.1089/tmj.2013.0337

30. Fox S, Duggan M. Mobile health 2012: Half of smartphone owners use their devices to get health information and onefifth of smartphone owners have health apps [Internet]. Washington (DC): Pew Research Center's Internet \& American Life Project; 2012 Nov 8. Available from: http://www.pewinternet.org/files/old-media/Files/Reports/ 2012/PIP MobileHealth2012 FINAL.pdf

31. Oslin DW, Sayers S, Ross J, Kane V, Ten Have T, Conigliaro J, Cornelius J. Disease management for depression and at-risk drinking via telephone in an older population of veterans. Psychosom Med. 2003;65(6):931-37.

[PMID:14645769]

http://dx.doi.org/10.1097/01.PSY.0000097335.35776.FB
32. Rosen CS, Tiet QQ, Harris AH, Julian TF, McKay JR, Moore WM, Owen RR, Rogers S, Rosito O, Smith DE, Smith MW, Schnurr PP. Telephone monitoring and support after discharge from residential PTSD treatment: A randomized controlled trial. Psychiatr Serv. 2013;64(1):13-20. [PMID:23117443]

http://dx.doi.org/10.1176/appi.ps.201200142

33. Zanjani F, Miller B, Turiano N, Ross J, Oslin D. Effectiveness of telephone-based referral care management, a brief intervention to improve psychiatric treatment engagement. Psychiatr Serv. 2008;59(7):776-81. [PMID:18586995] http://dx.doi.org/10.1176/ps.2008.59.7.776

34. McInnes DK, Petrakis BA, Gifford AL, Rao SR, Houston TK, Asch SM, O’Toole TP. Retaining homeless veterans in outpatient care: A pilot study of mobile phone text message appointment reminders. Am J Public Health. 2014;104(4 Suppl 4):S588-94. [PMID:25100425] http://dx.doi.org/10.2105/AJPH.2014.302061

35. Fjeldsoe BS, Marshall AL, Miller YD. Behavior change interventions delivered by mobile telephone short-message service. Am J Prev Med. 2009;36(2):165-73.

[PMID:19135907]

http://dx.doi.org/10.1016/j.amepre.2008.09.040

36. Krishna S, Boren SA, Balas EA. Healthcare via cell phones: A systematic review. Telemed J E Health. 2009; 15(3):231-40. [PMID:19382860] http://dx.doi.org/10.1089/tmj.2008.0099

37. Patrick K, Raab F, Adams MA, Dillon L, Zabinski M, Rock CL, Griswold WG, Norman GJ. A text message-based intervention for weight loss: Randomized controlled trial. J Med Internet Res. 2009;11(1):e1. [PMID:19141433] http://dx.doi.org/10.2196/jmir.1100

38. Campbell SW, Kelly MJ. Mobile phone use among Alcoholics Anonymous members: New sites for recovery. New Media \& Society. 2008;10(6):915-33. http://dx.doi.org/10.1177/1461444808096251

39. Riley W, Obermayer J, Jean-Mary J. Internet and mobile phone text messaging intervention for college smokers. J Am Coll Health. 2008;57(2):245-48. [PMID:18809542] http://dx.doi.org/10.3200/JACH.57.2.245-248

40. Erbes CR, Stinson R, Kuhn E, Polusny M, Urban J, Hoffman J, Ruzek JI, Stepnowsky C, Thorp SR. Access, utilization, and interest in mHealth applications among veterans receiving outpatient care for PTSD. Mil Med. 2014; 179(11):1218-22. [PMID:25373044] http://dx.doi.org/10.7205/MILMED-D-14-00014

41. Bush NE, Fullerton N, Crumpton R, Metzger-Abamukong M, Fantelli E. Soldiers' personal technologies on deployment and at home. Telemed J E Health. 2012;18(4):253-63. [PMID:22400971] http://dx.doi.org/10.1089/tmj.2011.0131 
42. Gowen K, Deschaine M, Gruttadara D, Markey D. Young adults with mental health conditions and social networking websites: Seeking tools to build community. Psychiatr Rehabil J. 2012;35(3):245-50. [PMID:22246123] http://dx.doi.org/10.2975/35.3.2012.245.250

43. Christensen H, Griffiths KM, Jorm AF. Delivering interventions for depression by using the internet: Randomised controlled trial. BMJ. 2004;328(7434):265-68. http://dx.doi.org/10.1136/bmj.37945.566632.EE

44. Haker H, Lauber C, Rössler W. Internet forums: A selfhelp approach for individuals with schizophrenia? Acta Psychiatr Scand. 2005;112(6):474-77. [PMID:16279878] http://dx.doi.org/10.1111/j.1600-0447.2005.00662.x

45. Proudfoot J, Klein B, Barak A, Carlbring P, Cuijpers P, Lange A, Ritterband L, Andersson G. Establishing guidelines for executing and reporting Internet intervention research. Cogn Behav Ther. 2011;40(2):82-97. [PMID:25155812] http://dx.doi.org/10.1080/16506073.2011.573807

46. Griffiths KM, Calear AL, Banfield M. Systematic review on Internet Support Groups (ISGs) and depression (1): Do ISGs reduce depressive symptoms? J Med Internet Res. 2009;11(3):e40. [PMID:19793719] http://dx.doi.org/10.2196/jmir.1270

47. Andersen RM. Revisiting the behavioral model and access to medical care: Does it matter? J Health Soc Behav. 1995;36(1):1-10. [PMID:7738325] http://dx.doi.org/10.2307/2137284

48. Brooks E, Novins DK, Thomas D, Jiang L, Nagamoto HT, Dailey N, Bair B, Shore JH. Personal characteristics affecting veterans' use of services for posttraumatic stress disorder. Psychiatr Serv. 2012;63(9):862-67. http://dx.doi.org/10.1176/appi.ps.201100444

49. Cully JA, Jameson JP, Phillips LL, Kunik ME, Fortney JC. Use of psychotherapy by rural and urban veterans. J Rural Health. 2010;26(3):225-33. [PMID:20633090] http://dx.doi.org/10.1111/j.1748-0361.2010.00294.x

50. Sayer NA, Clothier B, Spoont M, Nelson DB. Use of mental health treatment among veterans filing claims for posttraumatic stress disorder. J Trauma Stress. 2007;20(1):15-25. [PMID:17345650]

51. Harpaz-Rotem I, Rosenheck RA, Pietrzak RH, Southwick SM. Determinants of prospective engagement in mental health treatment among symptomatic Iraq/Afghanistan veterans. J Nerv Ment Dis. 2014;202(2):97-104. http://dx.doi.org/10.1097/NMD.0000000000000078

52. Spoont MR, Nelson DB, Murdoch M, Sayer NA, Nugent S, Rector T, Westermeyer J. Are there racial/ethnic disparities in VA PTSD treatment retention? Depress Anxiety. 2015; 32(6):415-25. [PMID:25421265]

http://dx.doi.org/10.1002/da.22295

53. Cully JA, Tolpin L, Henderson L, Jimenez D, Kunik ME, Petersen LA. Psychotherapy in the Veterans Health Admin- istration: Missed opportunities? Psychol Serv. 2008;5(4): 320-31. [PMID:25177213]

http://dx.doi.org/10.1037/a0013719

54. Elhai JD, Don Richardson J, Pedlar DJ. Predictors of general medical and psychological treatment use among a national sample of peacekeeping veterans with health problems. J Anxiety Disord. 2007;21(4):580-89. [PMID:16965892] http://dx.doi.org/10.1016/j.janxdis.2006.07.001

55. Naragon-Gainey K, Hoerster KD, Malte CA, Jakupcak M. Distress symptoms and high-risk behaviors prospectively associated with treatment use among returning veterans. Psychiatr Serv. 2012;63(9):942-44. [PMID:22810211] http://dx.doi.org/10.1176/appi.ps.201100349

56. Elhai JD, Grubaugh AL, Richardson JD, Egede LE, Creamer M. Outpatient medical and mental healthcare utilization models among military veterans: Results from the 2001 National Survey of Veterans. J Psychiatr Res. 2008; 42(10):858-67. [PMID:18005993]

http://dx.doi.org/10.1016/j.jpsychires.2007.09.006

57. Mangione TW. Mail surveys. In: Bickman L, Rog DJ, editors. Handbook of applied social research methods. Thousand Oaks (CA): Sage Publications; 1998. p. 399-427.

58. Weathers FW, Huska J, Keane T. PCL-C for DSM-IV. Boston (MA): National Center for Posttraumatic Stress Disorder, Behavioral Science Division; 1991.

59. Bliese PD, Wright KM, Adler AB, Cabrera O, Castro CA, Hoge CW. Validating the primary care posttraumatic stress disorder screen and the posttraumatic stress disorder checklist with soldiers returning from combat. J Consult Clin Psychol. 2008;76(2):272-81. [PMID:18377123] http://dx.doi.org/10.1037/0022-006X.76.2.272

60. Jakupcak M, Hoerster KD, Varra A, Vannoy S, Felker B, Hunt S. Hopelessness and suicidal ideation in Iraq and Afghanistan War Veterans reporting subthreshold and threshold posttraumatic stress disorder. J Nerv Ment Dis. 2011;199(4):272-75. [PMID:21451353] http://dx.doi.org/10.1097/NMD.0b013e3182124604

61. Blanchard EB, Jones-Alexander J, Buckley TC, Forneris CA. Psychometric properties of the PTSD Checklist (PCL). Behav Res Ther. 1996;34(8):669-73. [PMID:8870294]

62. DuHamel KN, Ostrof J, Ashman T, Winkel G, Mundy EA, Keane TM, Morasco BJ, Vickberg SM, Hurley K, Burkhalter J, Chhabra R, Scigliano E, Papadopoulos E, Moskowitz $\mathrm{C}$, Redd W. Construct validity of the posttraumatic stress disorder checklist in cancer survivors: analyses based on two samples. Psychol Assess. 2004;16(3):255-66. [PMID:15456381]

63. Graham JW. Missing data analysis: Making it work in the real world. Annu Rev Psychol. 2009;60:549-76.

[PMID:18652544]

http://dx.doi.org/10.1146/annurev.psych.58.110405.085530 
64. Brown MC, Creel AH, Engel CC, Herrell RK, Hoge CW. Factors associated with interest in receiving help for mental health problems in combat veterans returning from deployment to Iraq. J Nerv Ment Dis. 2011;199(10):797-801. [PMID:21964275] http://dx.doi.org/10.1097/NMD.0b013e31822fc9bf

65. McInnes DK, Gifford AL, Kazis LE, Wagner TH. Disparities in health-related internet use by US veterans: Results from a national survey. Inform Prim Care. 2010;18(1):59-68. [PMID:20429979]

66. Tsai J, Rosenheck RA. Use of the internet and an online personal health record system by US veterans: Comparison of Veterans Affairs mental health service users and other veterans nationally. J Am Med Inform Assoc. 2012;19(6): 1089-94. [PMID:22847305] http://dx.doi.org/10.1136/amiajnl-2012-000971

67. Tsai J, Klee A, Rosenheck RA, Harkness L. Internet use among veterans with severe mental illness. Psychiatr Serv. 2014;65(4):564-65. [PMID:24687114] http://dx.doi.org/10.1176/appi.ps.201300432

68. Hoerster KD, Malte CA, Imel ZE, Ahmad Z, Hunt SC, Jakupcak M. Association of perceived barriers with prospective use of VA mental health care among Iraq and Afghanistan veterans. Psychiatr Serv. 2012;63(4):380-82. [PMID:22476304] http://dx.doi.org/10.1176/appi.ps.201100187

69. Torkzadeh G, Chang JC, Demirhan D. A contingency model of computer and Internet self-efficacy. Inf Manage. 2006;43(4):541-50. http://dx.doi.org/10.1016/j.im.2006.02.001

70. Torkzadeh G, Van Dyke TP. Effects of training on Internet self-efficacy and computer use attitudes. Comput Human
Behav. 2002;18(5):479-94.

http://dx.doi.org/10.1016/S0747-5632(02)00010-9

71. Xie B. Experimenting on the impact of learning methods and information presentation channels on older adults' ehealth literacy. J Am Soc Inf Sci Technol. 2011;62(9): 1797-1807. http://dx.doi.org/10.1002/asi.21575

72. Brooks E, Turvey C, Augusterfer EF. Provider barriers to telemental health: Obstacles overcome, obstacles remaining. Telemed J E Health. 2013;19(6):433-37.

[PMID:23590176]

http://dx.doi.org/10.1089/tmj.2013.0068

Submitted for publication April 25, 2014. Accepted in revised form June 3, 2015.

This article and any supplementary material should be cited as follows:

Whealin JM, Seibert-Hatalsky LA, Howell JW, Tsai J. Emental health preferences of Veterans with and without probable posttraumatic stress disorder. J Rehabil Res Dev. 2015;52(6):725-38.

http://dx.doi.org/10.1682/JRRD.2014.04.0113

ResearcherID: Julia M. Whealin, PhD: J-8819-2015; Jack Tsai, PhD: D-3889-2013

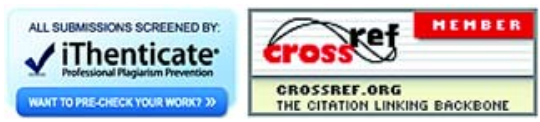


